\title{
Construction and Practice of the Self-Evaluation System of Colleges and Universities based on the Quality
}

\author{
Zhaohong Liu, ${ }^{1, a}$, Yang Yang ${ }^{1, b}$ and ShipingLiu, ${ }^{1, c}$ \\ ${ }^{1}$ Chengdu Neusoft University, Chengdu, Sichuang, China, Zip Code: 611844 \\ aliuzhaohong@tsinghua.org.cn, byangyang@nsu.edu.cn, cliushiping@nsu.edu.cn
}

Keywords: Quality; Self-evaluation system; Evaluation framework model; Multiple subjects

\begin{abstract}
In the process of the transformation of higher education from elite education to popularization, we discussed the goal of the self-evaluation system of colleges and universities, conceived a learning-oriented self-assessment framework model, constructed the organizational structure of teaching evaluation with the participation of multiple subjects, improved the evaluation standards and evaluation programmed, formed the operating mechanism of self-assessment system characterized by "self-improvement and self-improvement". It is of great significance to deepen education reform and improve education quality in universities.
\end{abstract}

\section{Introduction}

The Declaration of the World Conference on Higher Education indicated that it will pay a huge price for who to neglect quality. To guarantee the quality of education, most of universities have ushered in an era of external evaluation. The external assessment is dominated by the government, society and the media, which is highly valued by the institutions of higher education and its competent authorities, and has also attracted wide attention from the society ${ }^{[1]}$. But the essence of evaluation is distorted by external assessment, making the self - assessment as an embellishment, foil, or vassal of an external assessment ${ }^{[2]}$. This has aroused the great importance that our government clearly requires that establishment of an evaluation system based on the self-assessment of universities. Therefore, it is great significance in theory and practice to construct and practice the self-evaluation system of universities with the core of quality.

\section{Why Build a Self-Evaluation System for Universities}

After the human capital theory was put forward in 1950s, with the rapid development of higher education from elite education to popularization has brought the quality crisis, which has led to the trust crisis and the demand for quality protection become the focus of social concern. External evaluation resulting from the accountability of educational quality that has a certain impact on the quality of higher education, which is based on external, internal and independent evaluation activities, is represented by accreditation, ranking and performance evaluation. However, this assessment shows more about the position of the government, the society and the public. It is not focusing on the assessment itself that how the quality to be promoted ${ }^{[3]}$.

Universities are the main body of education and teaching quality guarantee. In the universities, external quality assurance is the external factors, internal quality assurance is internal factors, and external only by internal factors can play a role ${ }^{[4]}$. External assessment is an indirect method to improve quality, and self-evaluation is the direct method to improve quality. There are some questions that every university need to consider that include what kind of university should establish, how to establish, what kind of people to cultivate and how to cultivate these people. But if we don't deeply reflect and answer the two fundamental questions about whether we have become a university with our goal and whether we cultivate the people we want, we can't form a stable closed loop in higher education. Both theory and practice have proved that higher education in the open-loop state is not stable, and impossible to develop continuously. Therefore, Universities should organize a self-evaluation system with core of quality, and carry out the comprehensive 
self-evaluation with the whole process and all staff. To achieve the goal of deepening the reform and improving the quality, we should find out the problems, analyze the problems and result the problems.

\section{How to Construct a Self-Evaluation System based on Quality}

Target Position. In Universities, the premise and foundation of the successful construction of the self- evaluation system lies in the accuracy of the target position. The positioning must be considered based on social and economic development. It must be consistent with the needs of social development, the trend of higher education and the mission of higher education ${ }^{[5]}$.Therefore, Chinese Universities should focus on the statement and strategic goal in this era, which should take the initiative to serve for regional economic development and social development, should make scientific analysis and research to identify the type of schooland the training objectives, and should be conceived, designed, constructed and perfected in the self-evaluation system based on the school and talent training goals. The implementation of the system mainly includes conception design, self-evaluation framework model, self-evaluation organization structure with multiple subjects involved, self-evaluation criteria and plans, self-improvement and self-improvement operating mechanism, and continuous improvement of teaching quality.

Evaluation Model. Based on the historical and realistic reasons, the leaders, teachers and students of universities need to learn constantly and need to study hard. In the process of learning, we should learn from the advanced experience of total quality management and global evaluation certification, integrate self-evaluation and learning, take self-evaluation as a major part of learning, cultivate evaluation ability as the key step to improve learning ability, and train evaluation ability can be run through the whole process of evaluation. It will systematically conceive, design and practice the "six assessment framework" model of evaluation target, assessment of the whole staff, evaluation of diversification, evaluation of informatization, evaluation of the whole process and assessment of learning.

This paper will introduce the most important of assessment learning link in the six majors' links model. Through self-assessment and self-management, leaders should constantly update management concepts, learn to appraise, evaluate teaching and evaluate learning, and understand the authenticity of education management, which to form a management cycle of goals, services, reflection and improvement, and learn to run schools that improve the quality of running schools and the benefits of running schools. Through self-evaluation and self-reform, teachers should constantly innovate teaching ideas, and gradually achieve the evaluation of management, evaluation of teaching, evaluation of learning. We should focus on teaching that transfer teaching to learning, and put all efforts to form teaching goals, learning services, rethinking and adjusting to improve the teaching cycle.

Through evaluation of management, evaluation of teaching and evaluation of learning, students will gradually realize the transition from passive management, passive education, passive learning to self-management, self-education and active learning. Students will not only reflect and evaluate others, but also reflect on and evaluate themselves. So that we can know ourselves comprehensively, objectively and fairly, and finally form the learning cycle of goal, action, reflection and improvement, which to improve learning effect. At the same time, we should require every teacher and student to master and utilize the evaluation tools and the tools of information technology, and use the information evaluation platform of the college to carry out self- assessment of target, whole process and diversification.

Structure of Organization. The foundation of "six assessment frameworks" model is informatization and the core is learning, which is a complicated system to carry out the full process of evaluation. It is very significant to ensure the effective operation of the self-evaluation system, to build a multi-level, reasonable and clear teaching evaluation structure.

First of all, at the school level, we should set up a vice president position in charge of teaching quality, and establish quality management institutions including teaching quality management and teaching security department, education and teaching evaluation committee, teaching and learning 
Liaison Committee and so on. Under the leadership of the vice president who is in charge of teaching quality, that the teaching quality management and teaching security department is responsible for the planning, creation, operation and evaluation of the security system of teaching quality, and organize the normalization activate of self-evaluation in school. Supervision committee of the education is directly led by the vice president, which the one of the duties is responsible for supervising and guiding the whole process of educational work, and guiding and evaluating the evaluation work. Its members are independent and have no administrative overlap with the supervised objects. The members include experts, professors, representatives of teachers and students, members from other functional departments, etc. The teaching and learning Liaison Committee is composed of students, which every major and every class should have student representative. The functions of the teaching and learning Liaison Committee include teaching and learning research, information investigation of teaching quality, evaluation of organization participation and so on.

Secondly, in each teaching department, educational and teaching evaluation teams should be set up respectively, whose main functions include supervision, guidance and teaching evaluation. The members include faculty leaders, experts and professors, representatives of teachers and students, representatives of other departments, etc.

Thirdly, main part of the overall assessment. The university should optimize the organizational structure with the students as the center, set up the professional education team, and avoid the "two skin" phenomenon of professional education and quality education. The universities also need to implement the integrated management model with professional as the basic education unit, which can integrate and promote each professional education and teaching activities. Team members should make joint efforts to achieve professional training goals from different perspectives. The team management model based on the major that enables the leaders, teachers and students to truly integrate into the education and teaching. Teachers and faculties are the main body of the education and teaching that centered on the students' learning. At the same time, they are the self-evaluators of the education and teaching life. Evaluation is both a value judgment and a valuable construction ${ }^{[6]}$.

Evaluation Standards. Evaluation standards and programs are the models of education and teaching objectives, teaching processes, links and quality monitoring. They reflect the direction and ideas of running universities, especially guide the all-round development of universities, teachers and students. Therefore, the evaluation standards should be in conformity with the actual work condition, the orientation of running a school, the goal of training talents, the requirements of the comprehensive development and the national regulations. There are multitude of works and activities in universities, and we only chose formulation of talent training program as an example that including industry research and demonstration, training objectives, curriculum design, credit exchange etc. The quality of education and teaching activities will affect the overall quality of the University. To evaluate its quality, the evaluation criteria need to be improved.

Operation Mechanism. The interaction and causality between different elements in the self-assessment system constitute the operation mechanism of self-improvement. Through the Education Supervision Committee and the teaching and learning Liaison Committee, we monitor the teaching situation and learning situation, compare the collected information with the evaluation criteria, and get suggestions and comments. On the one hand, the feedback is given to the department leaders, teachers and students that makes teachers' behavior and students' study improved continuously. On the other hand, the feedback is given to the quality department and the college leaders to modify and improve the evaluation standards and systems. The double closed loop structure of the self-evaluation system not only ensures the continuous improvement of the quality of education, but also guarantees the continuous improvement of the quality standard of education. It also protects itself from self-learning and self-improvement. In addition, the evaluation content can be easily adjusted by modifying and reducing the teaching situation and the learning situation, which is easy and flexible to dock with domestic and foreign assessment standards.

In the future, the competition of universities will be mainly reflected in the quality of education. The double closed loop structure and self-learning ability of the operation mechanism of the self- 
assessment system strongly guarantee the advantage of Chengdu Neusoft University in the competition of educational quality and take the initiative.

\section{Practice Effect}

The construction and practice of the self-evaluation system with the quality as the core fully guarantee that the reform of education and teaching, and the improvement of the quality of talent training.

Practice Situation. Institute of Chengdu Neusoft University has continuously explored the establishment and normalization of self-assessment system for 10 years, and systematically conceived, designed and implemented quality assessment and improvement work, providing a strong guarantee for training high-level applied talents. The evaluation criteria and corresponding implementation plans for education team, professional teachers, quality teachers, students, majors, courses, projects, teaching materials and so on were formulated. And the basic courses, core courses, projects, majors and teachers were evaluated in a planned way.

According to the evaluation results, the departments, teachers and students continue to improve, and the college will intensify the inspection and feedback. In the past 10 years, more than 1,000 issues have been investigated and dealt with. More than 2,000 of advice and suggestions from enterprises, students, teachers and experts have been processed by feedback, which has effectively promoted the improvement of teaching quality.

Practice Effect. By normalizing self-assessment, it has effectively promoted the quality consciousness of teachers and students, and formed the culture of quality is everything. The achievements of education and teaching are remarkable, and the employment rate and quality of the graduates have been greatly improved. The level of education and teaching quality are recognized by the government, the employers, the teachers and students, which increasing the satisfaction of the stakeholders.

\section{Conclusion}

The construction of aself-evaluation system in Universities is not only a theoretical problem, but also a management practice. After nearly 10 years of in-depth research and discussion, a lot of practical experience has been accumulated, which has gradually built a self-evaluation system with the characteristics of "self-proof, continuous improvement and a virtuous cycle of science". It is necessary to point out that the self-evaluation system of universities should think and plan from the perspective of building the quality security system of higher education. By learning from the external assessment and exceeding the assessment itself, the education and teaching reform can be deepened, and the quality of talent training can be steadily improved.

\section{Acknowledgements}

Funded Project: Research and Practice on the Quality Security System and Standards of College Teaching Quality

Department: The Scientific Research Project in 2013 from Sichuan Provincial Education Department

Project Number: 13SA0184

\section{References}

[1] B.L. Zhong: Analysis of Some Hot Issues in Undergraduate Teaching Evaluation, Research on Higher Education,(2009)No.6, p.38 45.

[2] Z.T. Liu: Characteristics and Implementation Strategies of Teaching Self-Assessment in Universities, Chinese Higher Education,(2013)No.7, p.42 45.

[3] Z.T. Liu: From the Symbolic Assessment to the Authenticity Assessment, Research on Higher 
Education,(2014) No.2, p.27 32

[4] Z.Y. Li, H. Zhu and Z.J. Liu: Where Should the Undergraduate Teaching Assessment Go in China, Development and Evaluation of Higher Education,(2011) No.6, p.1-10.

[5] B.L. Zhong, H.T. Zhou, Z. Liu and H. Wei: The experience and Lessons from Researching Background Trend and Innovation Evaluation idea--Basic Problems of Undergraduate Teaching Evaluation, Chinese Higher Education, (2009) No.1, p.31-34.

[6] B. Yi: Exploration and Practice of Teaching Quality Security System in Colleges Based on EC2000, Vocational education BBS,(2010) No.8, p.10-12. 